\title{
OTROS SUEÑOS DE LA RAZÓN
}

\author{
OTHER DREAMS OF REASON
}

José Fernández Vega ${ }^{1}$

Jonathan Crary, 24/7 Late Capitalism and the Ends of Sleep, Londres, Verso, 2013, 132 págs.

A fines de 2013, la prensa informó que una empleada de Indonesia había difundido por Twitter que llevaba trabajando treinta horas continuas en una agencia de publicidad y poco después murió de un ataque al corazón. Se había mantenido despierta consumiendo bebidas estimulantes. Aunque se trata de un ejemplo extremo, la noticia condensa algunos de los problemas que intenta analizar el libro de Jonathan Crary: la alteración de las relaciones laborales en el último cuarto de siglo, la relación adictiva con las máquinas y el exhibicionismo del yo en las redes sociales. Pero el tema central es el combate sistémico contra los límites biológicos que impone el cuerpo humano y la docilidad de los sujetos que se creen enteramente autónomos.

Profesor de historia y teoría del arte en la Universidad de Columbia desde hace casi veinticinco años, la tesis general de Crary gira en torno a una idea de Karl Marx hasta ahora insuficientemente valorada como plataforma de interpretación del mundo contemporáneo. Se trata del postulado, en cierta medida marginal en la propia obra de Marx, según el cual el capitalismo busca constantemente presionar sobre la biología con el fin de colonizarla. No solo se limita a usufructuar las riquezas naturales sin consideración por la renovación de los recursos o los efectos sobre el medioambiente. Se dirige muy especialmente a la biología humana, al cuerpo y a sus necesidades; pretende así derribar las "barreras naturales" a todo nivel.

\footnotetext{
${ }^{1}$ Doctor en filosofía; Pprofesor adjunto regular de estética en la Universidad de Buenos Aires (UBA), Es investigador de carrera (categoría independiente) del Consejo Nacional de Investigaciones Científicas y Técnicas (CONICET-UBA), Buenos Aires, DF, Argentina, e-mail: joselofer@gmail.com
} 
En el primer capítulo de esta obra se exponen de manera a la vez amena y enérgica los intentos del sistema capitalista por vencer al sueño, una necesidad básica de nuestra especie que, desde una perspectiva puramente capitalista, solo le quita horas al trabajo y al consumo. Es un tiempo extenso - un tercio de nuestras vidas, según se afirma-- e inútil, carente de productividad o crecimiento. Se encuentra asociado a la falta de actividad y a la culpa que ello genera bajo el régimen de la modernidad. Este primer capítulo es sin dudas el más vigoroso y concentrado de todo el libro.

Como sucedió con distintos desarrollos tecnológicos del pasado, la vanguardia en la investigación sobre el sueño la protagonizan los militares. Para ellos, explica Crary, sería fundamental contar con una fuerza de combate que no precise descanso ni reemplazo por durante un extenso período. De su lado, en la vida civil, a lo largo de todo el mundo desarrollado se registran alteraciones en el sueño entre la gente común y problemas con el descanso. En ocasiones, ello se debe a la interacción maníaca con la tecnología comunicacional omnipresente que, por ejemplo, lleva a la gente a levantarse en medio de la noche para consultar su correo electrónico. Por otra parte, la industria farmacéutica dispone de un vasto mercado y una variada oferta de somníferos; y también de estimulantes para mantener a las personas en actividad.

Se trata de garantizar el mayor rendimiento laboral y las más amplias oportunidades de consumo las veinticuatro horas del día los siete días de la semana. La modernidad avanzó lentamente hasta llegar a la mundialización de estilos, de modos de producción y de formas de consumo. De hecho, y a pesar de los proféticos anuncios globalizadores incluidos en el Manifiesto Comunista de 1848, la erradicación de un tipo de sociedad más inclinada a la periodización de la vida sobre la base de las estaciones del año, habituada al trabajo pero también al ocio y a la fiesta, no se completó en Occidente sino después de la Segunda Guerra Mundial, sostiene Crary, quien se respalda en distintos autores, si bien sus citas bibliográficas son restringidas. Con la caída del comunismo a comienzos de 1990, y el inmediato despliegue de un neoliberalismo que estableció un mercado mundial sin límites, la utopía expansiva del capitalismo no sólo 
alcanzó todos los rincones de la tierra sino también al entero cuerpo de los seres humanos que la habitan.

Desde el punto de vista de los individuos, una vida activa de veinticuatro horas sobre veinticuatro puede generar la ilusión de disponer de más tiempo para la realización personal y una mayor intensidad existencial. El descanso pasó a ser considerado como un período muerto, infructuoso, incluso vergonzante. Crary habla de la prehistoria de estas concepciones, cuyo primer gran hito fue la iluminación pública de las ciudades. Con ella, de pronto, aumentó el consumo, la oferta de entretenimiento y, desde luego, la productividad económica y la seguridad urbana. La historia contemporánea registra otros hechos vinculados a la ausencia de sueño, y más atroces. La interrupción del sueño, la iluminación permanente de la celda, el ruido o la música constante y a todo volumen que no permiten descansar constituyen una variante de la tortura bien conocida y ampliamente aplicada desde 2001, escribe Crary. La privación sensorial, la supresión de la diferencia entre el día y la noche, se halla asimismo garantizada en las grandes tiendas o en los casinos.

Los efectos subjetivos de este nuevo paisaje social son la indiferencia, el aislamiento personal y el malestar general. Crary apela a una serie de filósofos, desde Descartes a Levinas, para resaltar la importancia del sueño como tema teórico en la historia del pensamiento. El argumento del autor recurre asimismo a una serie de obras de arte. Entre ellas a Solaris, la película de Andrei Tarkovsky, que muestra a una comunidad sometida al insomnio crónico y expuesta a la perpetua luz diurna; o a El castillo de Kafka, donde insomnio y extrañamiento son parte de la dialéctica de la modernidad insinuada en la novela.

Crary propone su libro como una historia cultural y política de las imágenes técnicas de la vigilia social moderna. Examina la metafórica de la luz y el despertar, tan importantes para la filosofía como para la política modernas. En contraste, la consigna "24/7" anuncia, como se señala en el segundo capítulo, "un tiempo sin tiempo". En el plano espacial, implica una supresión de la singularidad de lugares y hechos. Llevado a su expresión militar, el dominio de la noche puede producir victorias arrasadoras, pero también reacciones inesperadas, 
como la ira cultural de tribus afganas frente a los ataques nocturnos indiscriminados de los estadounidenses, comenta Crary. La ampliación del tiempo, ínsita en la noción de 24/7, conduce en realidad a una disminución, antes que a una expansión, de la percepción individual y de las capacidades mentales. Por otro lado, la veloz transición tecnológica genera la imposibilidad de adaptación plena o familiarización con los nuevos aparatos y, al mismo tiempo, genera la sensación de que son éstos los que guían la historia humana en un proceso autopoiético. Además, las propias teorías que pretenden mantenerse al tanto de lo que ocurre para dar cuenta de lo contemporáneo se suelen volver rápidamente tan obsoletas como los nuevos artículos o procesos tecnológicos que describen. De allí se deriva que la capacidad de reflexión ha mermado, tanto a nivel teórico como, en general, también en un plano personal. El tiempo y la experiencia personales han sido capturados por la lógica de consumo vertiginoso, y ella obstaculiza todo pensamiento no asociado a dicha lógica.

La docilidad personal es la consecuencia de todo este complejo proceso que pone en juego la sociología de los aparatos, la filosofía del tiempo, la antropología de la experiencia y las visiones de la política. Hay una escena nueva en la cual no se trata tanto, como antaño, de que los consumidores acumulen objetos, sino de una adaptación subjetiva a aplicaciones y redes. Mientras se sigue sosteniendo una auto-imagen de independencia, la frontera que separaba el tiempo de trabajo del tiempo de ocio terminó colapsando, así como la que dividía lo público de lo privado. El marketing puede calcular las inclinaciones de cualquier individuo a partir de sus opciones en internet, e incluso trata de afinar la información mediante una "ergonómica óptica" que registra cada movimiento del ojo frente a cualquier pantalla. La homogeneización de la existencia va acompañada de una sensación de inevitabilidad, puesto que no parece haber opciones vitales por fuera del capitalismo de consumo y su adictiva interconexión digital.

Este capitalismo non-stop, según se advierte en el tercer capítulo, tiene como primer requisito la progresiva disolución de la relación con la tierra. La industrialización del campo siguió a la urbana. El factor tiempo devoró al espacio, y la abstracción se volvió un rasgo bá- 
sico del capitalismo. Pero la actual homogeneización del espacio sólo es el resultado de un largo proceso a lo largo del cual espacio y tiempo se mantuvieron históricamente desarticulados. Crary aplica aquí la noción de "vida cotidiana" que Henri Lefebvre puso en circulación en los años 1950, cuando se trataba de comprender y resistir a su colonización mercantil mientras en los hogares se difundía la televisión, un dispositivo aún fijado en el espacio, "anti-nomádico" y algo disfuncional para la tecnología que vino después. La década del sesenta vio surgir rebeliones, incluso teóricas, que intentaron combatir dicha colonización; pero a partir de los años 1980, ella se volvió irrefrenable.

La sociedad disciplinaria estudiada por Foucault, en la cual algunas instituciones operaban como factores de orden, se convirtió en una sociedad de control (el término fue propuesto en los años 1990 por Deleuze) donde todo momento y todo espacio pueden, en principio, ser objeto de vigilancia. Contemporáneamente, se desarrollaba una ampliación de las posibilidades particulares de comunicación y consumo hasta llegar al modelo 24/7. La sociedad del espectáculo descripta por Guy Debord había pasado de lo difuso a lo integral, como este autor alcanzó a ver hacia 1989 cuando revisó su célebre obra sobre el tema. Sin embargo, aclara Crary, el sueño es la única barrera natural que todavía parecía insuperable para un mercado, ahora financiero y global, que operaba 24/7. Entretanto, también se ha verificado un giro hacia la economía de la atención, cuyo objetivo, como se anticipó más arriba, era el conocimiento primero, y el dominio después, de los movimientos del globo ocular. Fue entonces cuando también surgió la posibilidad técnica de rodear al individuo de un mundo de aparatos que fueran tan móviles como él mismo. Se superaba así el modelo demasiado sedentario de la TV, dominante desde los años 1950. Crary, en unos pasajes muy agudos, hace un contraste sistemático entre la TV e Internet. Esta última, señala, nos despoja del tiempo vacío o libre, nos impulsa a la repetición y a la ilusión de superar la monotonía en el próximo click.

Todos estos análisis llevan al autor a redimir el concepto de reificación, marginado en las últimas décadas por la teoría. A ello consagra el último capítulo de su libro, donde se ponen en juego 
una cantidad de referencias literarias y cinematográficas, como por ejemplo la novela ¿Acaso los androides no sueñan con ovejas eléctricas? de Philip K. Dick y la película Blade Runner, de Ridley Scott, que pretendía ser la adaptación fílmica de esa novela pero que, según Crary, en realidad traicionó completamente el costado crítico de Dick. En un plano general, concluye el autor, la modernidad implicó un empobrecimiento perceptivo y un desprecio al sueño como fuente autorizada de experiencia. Para justificar este desenlace se contrastan las concepciones de Freud y los surrealistas, conectadas, pero también en conflicto, en sus respectivas valorizaciones del sueño. El giro tiene implicancias políticas. Condujo, como advirtió Italo Calvino, a la pérdida de la capacidad de ensoñación. En otro plano, significó una ofensiva cultural dirigida a desacreditar los valores, las esperanzas y las prácticas críticas surgidas en Occidente en los años 1960. El ideal que vino a sustituir nociones como la de vida comunitaria es el de la libertad respecto de los demás (pero no respecto de las imposiciones del mercado). Crary recurre al Sartre de la Crítica de la razón práctica para elucidar las posibilidades que conserva la acción política colectiva. Los conceptos sartreanos le permiten confirmar la idea de que la denominada "comunicación" no es más que una ilusión contemporánea, puesto que lo que en realidad predomina es una especie de autismo masivo e interconectado.

La perplejidad que suscita el mundo contemporáneo con sus vertiginosos cambios y la incorporación permanente de una tecnología cada vez más sorprendente, así como las nuevas configuraciones a la vez subjetivas y sociales que se generan, aspiran a ser relevadas y clarificadas por una cada vez más amplia bibliografía. Pero el ensayo de Crary no busca simplemente registrar unas mutaciones o sorprender mediante nuevas nociones. Aborda un tema concreto y original, el sueño, e intenta presentar las consecuencias -sociales y subjetivas - del cambio en la relación cultural y económica de los seres humanos con el descanso en nuestra época. Amena para la lectura y original en su aproximación, el tema general de esta obra reviste mucha actualidad ya sea para el análisis de la vida cotidiana en las sociedades posmodernas como para la evaluación de las trans- 
formaciones a todo nivel, tanto en el plano subjetivo como, más en general, aquellas experimentadas por el mundo del trabajo.

Recebido: 19/05/2014

Aprovado: 04/07/2014 
